\title{
Papers
}

\section{Inappropriate phosphate excretion in idiopathic hypercalciuria: the key to a common cause and future treatment?}

\author{
C P Williams, D F Child, P R Hudson, L De Soysa, G K Davies, M G Davies, \\ A R De Bolla
}

\begin{abstract}
Aims-To present experimental evidence in support of a proposed common cause for absorptive hypercalciuria, renal hypercalciuria, renal phosphate leak and enhancement of $1,25-(\mathrm{OH})_{2}$-vitamin $\mathrm{D}$ concentrations in patients presenting with renal stone disease; and to suggest further investigation with a view to new management.

Methods-An oral calcium loading test was administered to 15 patients with renal stones and 10 normal controls in the fasting state: urine and blood were collected hourly. After the second urine sample, 400 mg calcium dissolved in water was administered orally. Serum calcium, albumin, parathyroid hormone (PTH), and phosphate were measured together with urine calcium clearance and urinary phosphate from which the $\mathrm{TmPO}_{4}$ /glomerular filtration rate (GFR) ratio was calculated. Serum $1,25-(\mathrm{OH})_{2}$-vitamin $D$ was measured in the first serum sample. In addition, 24 hour urine calcium results were collected retrospectively from the patients' case notes over the previous 18 months.
\end{abstract}

Department Medical Biochemistry, Maelor Hospital NHS Trust, Croesnewydd Road, Wrexham LL13 7TD C P Williams

P R Hudson

G K Davies

M G Davies

Department of

Medicine

D F Child

L De Soysa

Department of Urology

A R De Bolla

Correspondence to: Dr C P Williams.

Accepted for publication 12 August 1996
Results-In the basal state, renal stone patients had an overall greater phosphaturia (lower $\mathrm{TmPO}_{4} / \mathrm{GFR}$ : median 1.72 compared with 2.10 in controls) and increased calcium clearance. Serum corrected calcium and PTH concentrations did not differ between the groups. After calcium loading, serum calcium and urine calcium clearance rose in both groups, with patients with renal stones experiencing a greater percentage fall in phosphaturia. In both groups $\mathrm{TmPO}_{4} / \mathrm{GFR}$ fell (greater phosphaturia) with increased serum corrected calcium, with the patients showing notably greater phosphaturia for any given calcium concentration. Patients also had notably greater phosphaturia compared with the serum calcium concentration for any given PTH value. Serum $1,25-(\mathrm{OH})_{2}$-vitamin $D$ was higher in patients than controls and for any $1,25-(\mathrm{OH})_{2}$-vitamin $\mathrm{D}$ concentration phosphaturia measured against serum calcium was greater in patients than controls. 1,25-(OH $)_{2}$-vitamin D did not correlate with phosphaturia relative to serum calcium concentrations within the patient and control groups.

Conclusions-It is proposed that patients with idiopathic hypercalciuria have an 'inappropriately' high phosphate excretion for any given serum calcium concentration. Loss of phosphate may induce increased activation of $1,25-(\mathrm{OH})_{2}-$ vitamin D. Some of the commonly described causes of stone formation may be manifestations of a single mechanism. (F Clin Pathol 1996;49:881-888)

Keywords: inappropriate phosphaturia, idiopathic hypercalciuria, renal calculi.

In the industrialised world up to $10 \%$ of men and $3 \%$ of women have a renal stone at some time during their life. ${ }^{1-5}$ Few renal stones are associated with early skeletal remains. Most stones $(80 \%)$ are calcium oxalate ${ }^{1}$ and up to half the patients are said to have hypercalciuria. Such patients have been classified ${ }^{6}$ as having either absorptive hypercalciuria, renal hypercalciuria, renal phosphate leak, or primary enhancement of 1,25 dihydroxycholecalciferol $\left(1,25-(\mathrm{OH})_{2}\right.$-vitamin $\left.\mathrm{D}\right)$ production. We find most patients with calcium stone disease will show hypercalciuria if observed for long enough. We present observations using the ratio of maximum rate of tubular reabsorption of phosphate to glomerular filtration rate $\left(\mathrm{TmPO}_{4} / \mathrm{GFR}\right)^{7}$ as an index of physiological regulation of phosphate clearance via the kidney.

The nutritional requirements of contemporary humans developed in an environment high in calcium. ${ }^{8}$ The stone age diet probably contained $2-3 \mathrm{~g}$ calcium per day and it is suggested that an intestinal absorption barrier and inefficient renal calcium conservation ${ }^{910}$ is a reflection of this. The hunter/gatherer diet would be relatively rich in natural phytates binding calcium. This would reduce the 


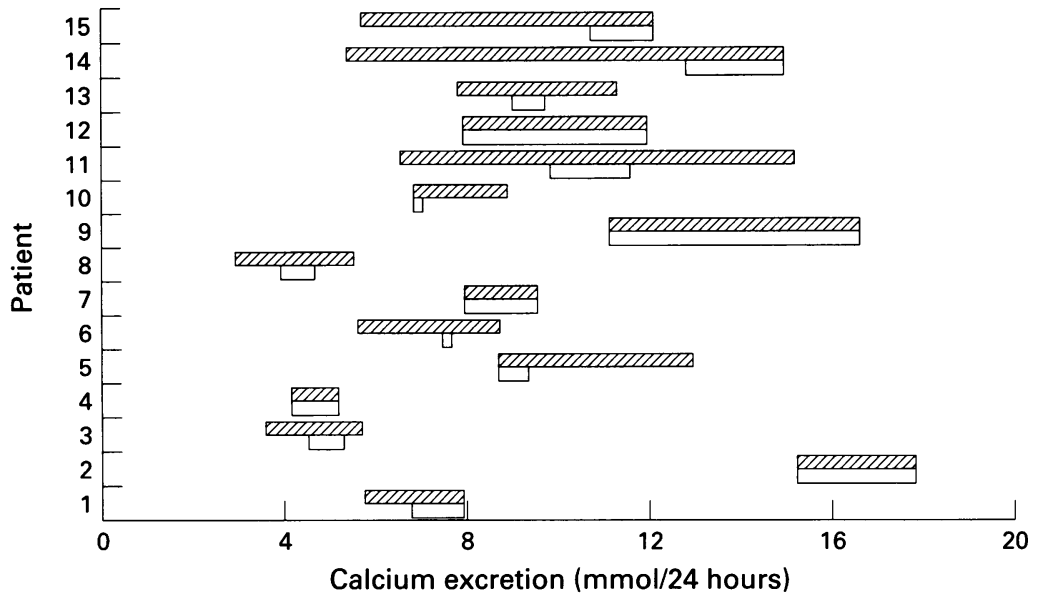

Figure 1 Inter-and intra-individual variation in calcium excretion in patients. The solid bars represent the lowest to highest urine calcium excretion over an 18 month follow up period; the unshaded bars represent the lower and higher of the most recent two consecutive daily urine collections prior to being recruited into the study.

Table 1 Components of variance in 24 hour urine calcium excretion results in patients on long term follow up, comparing results from urine samples collected on two consecutive days with results pooled from an 18 month follow up period. Vg, Vi and Va: inter-, intra- and analytical variance, respectively; $C V g, C V i$ and $C V a:$ inter-, intra- and analytical coefficients of variance, respectively. The findings of this study are presented together with abstracted data (as indicated) from the study by Shephard et al ${ }^{20}$

\begin{tabular}{|c|c|c|c|c|c|c|}
\hline & \multicolumn{2}{|c|}{ Interindividual } & \multicolumn{2}{|c|}{ Intra-individual } & \multicolumn{2}{|c|}{ Analytical } \\
\hline & $V g$ & $C V g$ & $V i$ & $C V i$ & $\mathrm{Va}$ & $\mathrm{CVa}$ \\
\hline \multicolumn{7}{|c|}{$\begin{array}{l}\text { Most recent pairs of data } \\
\text { (short term variation) }\end{array}$} \\
\hline Present study & 11.75 & $36.8 \%$ & 2.39 & $16.6 \%$ & 0.0036 & $2.10 \%$ \\
\hline Shephard et al ${ }^{20}$ & 2.03 & $26.9 \%$ & 1.77 & $25.1 \%$ & 0.002 & $1.37 \%$ \\
\hline \multicolumn{7}{|c|}{$\begin{array}{l}18 \text { Months' accumulated } \\
\text { data (long term variation) }\end{array}$} \\
\hline Present study & 8.91 & $37.6 \%$ & 3.6 & $23.9 \%$ & 0.0036 & $2.10 \%$ \\
\hline Shephard et al ${ }^{20}$ & 2.10 & $27.8 \%$ & 1.93 & $26.7 \%$ & 0.002 & $1.37 \%$ \\
\hline
\end{tabular}

amount of calcium that was absorbed overall and might delay the absorption of calcium, providing a steady release of calcium over a longer period than would otherwise be the case. The modern diet has vitamin $\mathrm{D}$ supplementation with an average intake of $3 \mu \mathrm{g}(120$ IU) per day ${ }^{11}$; of relevance, a mean supplement of under $25 \mu \mathrm{g}$ (1000 IU) per day ${ }^{12}$ has been associated causally with renal stones. Addition of dietary vitamin $\mathrm{D}$ is regarded as a convenient way of preventing deficiency, but it is of

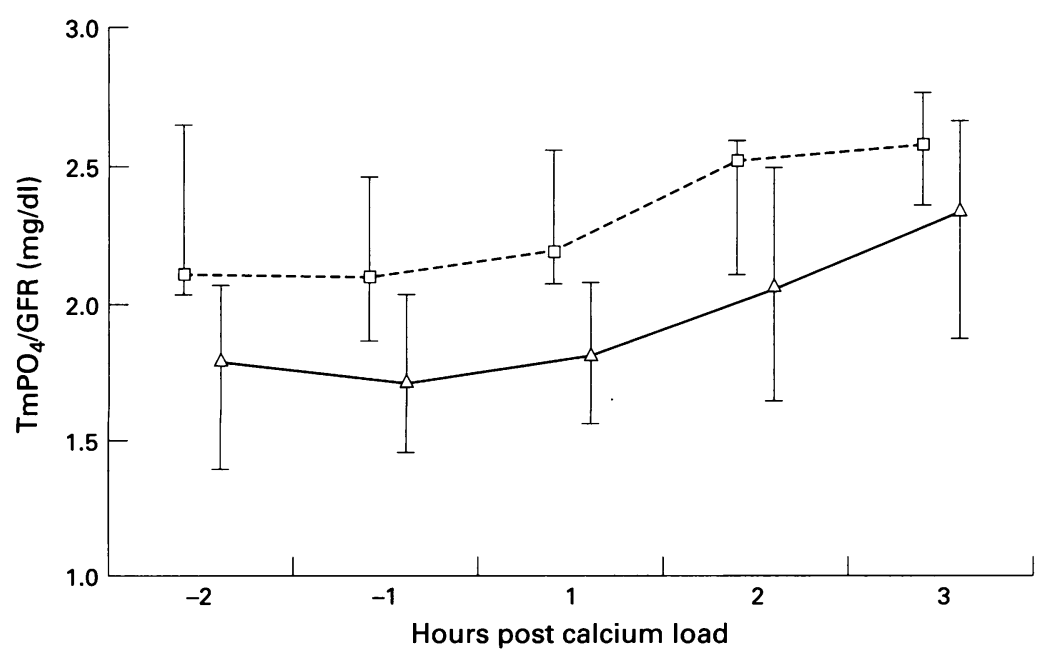

Figure 2 Response profiles of control and patient $\mathrm{TmPO}_{4} / \mathrm{GFR}$ results during the calcium loading test. The controls are represented by the broken line and the patients by the solid line. The vertical bars represent the upper and lower quartile values and are divided at the median points. particular interest that Fraser ${ }^{13}$ notes that none of the terrestrial vertebrates maintain their vitamin $\mathrm{D}$ status from a nutritional source and renal stones seem to be very rare in our closest primate relatives (personal communications: Mr A Greenwood, International Zoo Veterinary Group, Keighley; Ms A Caseldine, Wildlife Information Network, Royal Veterinary College, London; Mr T Sainsbury, Institute of Zoology, London; Mr D G Lyon, North West Zoological Society, Chester Zoo, Chester).

We postulate that a single underlying mechanism could be responsible for the previous conventional idiopathic hypercalciuria divisions and whether the same person may absorb and handle calcium differently at different times, subject to the 'set' of their gut absorption processes. The $\mathrm{TmPO}_{4} / \mathrm{GFR}$ ratio has been measured in patients with renal
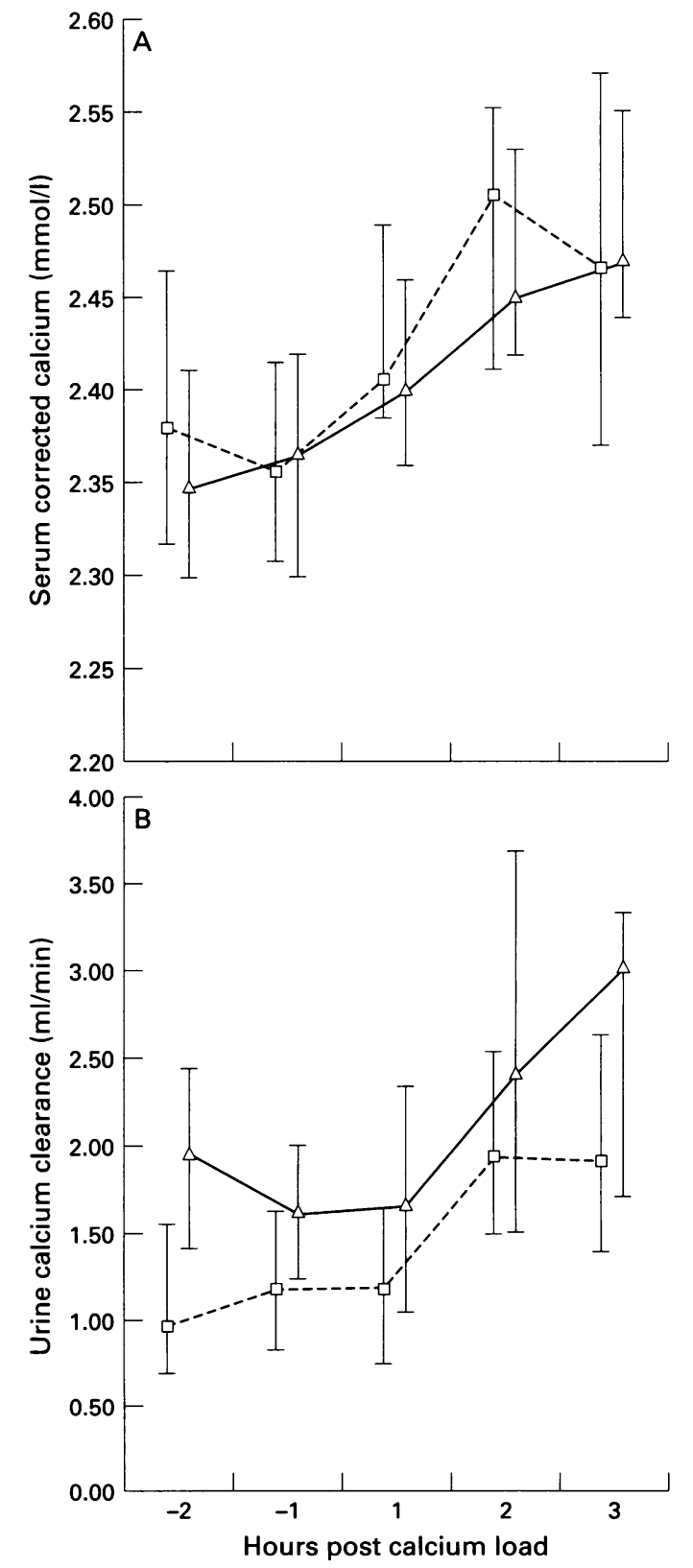

Figure 3 Response profiles of $(A)$ control and patient serum corrected calcium results and $(B)$ their urine calcium clearance results during the calcium loading test. The controls are represented by the broken lines and the patients by the solid lines. The vertical bars represent the upper and lower quartile values and are divided at the median points. 


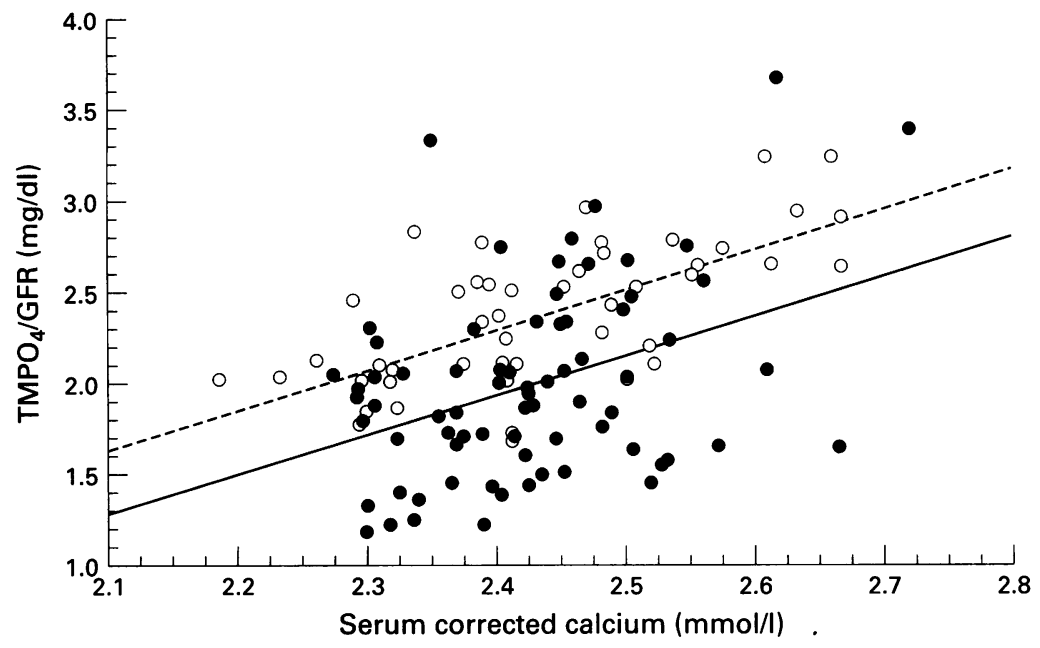

Figure 4 Scatter diagrams and regression lines of $\mathrm{TmPO}_{4} / \mathrm{GFR}$ against serum corrected calcium using data pooled from the calcium loading test results. The filled points represent patients' results and the unfilled points represent the controls' results. Their two regression lines are indicated by solid and broken lines, respectively.

stones based on the assumption that the degree of phosphaturia and the effects of calcium load upon it is under the regulation of parathyroid hormone (PTH). PTH suffers the disadvantage of episodic release and that there are a number of fragments, the specific roles of which have not been defined in their entirety. $\mathrm{TmPO}_{4} / \mathrm{GFR}$ as the physiological index has advantages over other indexes of phosphate excretion. ${ }^{7}$ It is appreciated that there are limitations to the presumed role of PTH in phosphate regulation. ${ }^{1415}$

\section{Methods}

SELECTION OF SUBJECTS

Ethics committee approval was obtained. Fifteen patients with confirmed renal stone disease were recruited. All patients had had raised 24 hour urinary calcium excretion at some stage (male $>7.5$ and female $>6.25$ $\mathrm{mmol} / 24$ hours) in their management, together with raised or normal oxalate. Anatomical defects, urinary tract infection, renal tubular acidosis (normal 24 hour urine citrate $\times 4$ ), hyperuricosuria, or cystinuria were excluded. There were 14 men and one woman with a median age of 46.3 years (range 22.7-74.6 years). None were in receipt of vitamin supplements. A normal control group was recruited from hospital staff, comprising seven men and three woman with a median age of $\mathbf{4 2 . 5}$ years (range 28-51 years). They had no history of renal stones or systemic disorders, had normal routine biochemistry profiles, and were not receiving medication.

Control subjects and patients were collected on a random opportunist basis. No person nor any of their data items were excluded from the results, except where specifically indicated.

CALCIUM EXCRETION STUDIES

Patients were asked to collect two 24 hour urine samples on consecutive days prior to their outpatient appointments. In the 18 months prior to the study, patients collected between two and 14 urine samples (median four).
CLEARANCE STUDIES DURING ORAL CALCIUM LOADING

Subjects fasted overnight (from 22.00 hours) but drank water as desired. Starting with an empty bladder at 08.30 hours the next day, urine was collected at one hourly intervals for five hours while drinking water (aiming to passing $120 \mathrm{ml}$ urine per hour). After the first two hours, one Calcium-Sandoz tablet (400 $\mathrm{mg}$ calcium) was given dissolved in $150 \mathrm{ml}$ water. Blood was taken within each hour via an indwelling cannula filled with Hepsal (10 units/ml; C P Pharmaceuticals, Wrexham, Clwyd, UK) to prevent clotting.

\section{LABORATORY ANALYSES}

Serum calcium, albumin and phosphate, and urine calcium, phosphate and creatinine were measured by standard laboratory procedures. Serum calcium was corrected for the serum albumin concentration using a relation derived from a local population study: corrected calcium $=$ serum total calcium - (albumin $x$ $0.017)+0.692$. Urine calcium clearance (in $\mathrm{ml} / \mathrm{minute}$ ) and $\mathrm{TmPO}_{4} / \mathrm{GFR}$ (in $\mathrm{mg} / \mathrm{dl}$ ) ${ }^{7}$ were also calculated.

Intact PTH was measured by a two-site immunochemiluminometric assay (Ciba Corning Diagnostics Ltd, Halstead, Essex, UK; CO9 2DX) and 1,25 dihydroxycholecalciferol was measured by radioimmunoassay (Immunodiagnostic Systems, Boldon, Tyne and Wear, UK).

\section{STATISTICAL METHODS}

Descriptive statistics, between group comparisons (Mann Whitney $U$ test) and regression analysis were carried out using the Statistica/W statistics package (StatSoft, Letchworth, Herts, UK). Median values are presented with their appropriate interquartile ranges. Comparisons between regression lines were performed using confidence intervals ${ }^{16}$ Inter- and intra-individual variations in calcium excretion were calculated using a type II (random effects) analysis of variance model. ${ }^{17} 18$ Analytical variation was calculated from internal quality control results during the study. Response profiles arising from the calcium loading test were tested for parallelism and vertical difference using multivariate profile analysis. ${ }^{19} \mathrm{Ma}-$ trix inversion and multiplication were performed using a spreadsheet (Quattro Pro v6.0, Novell UK, Bracknell, Berkshire, UK).

\section{Results}

Figure 1 shows inter- and intra-individual variation in calcium excretion in duplicate, consecutive 24 hour urine collections and in results collected over an 18 month period. Table 1 shows components of variance calculated from these data, together with comparison data from a study of normal subjects..$^{20}$ The interindividual coefficient of variation (CV) was similar in the paired urine values and in data accumulated over 18 months, but the intra-individual $\mathrm{CV}$ was $44 \%$ higher in the latter. 
The basal $\mathrm{TmPO}_{4} / \mathrm{GFR}$ ratio was calculated by taking the median of the first two hours' results during a calcium loading test. The control group had a higher basal $\mathrm{TmPO}_{4} / \mathrm{GFR}$ than the patient group (controls: median 2.10, intraquartile range 2.01-2.65; patients: median 1.72 , intraquartile range $1.45-2.04 ; \mathrm{p}=0.017$, Mann Whitney $U$ test), indicating that the patients had a greater basal phosphaturia than the controls.

Figure 2 shows the response profiles of $\mathrm{TmPO}_{4} / \mathrm{GFR}$ in patients and controls during the calcium loading test. $\mathrm{TmPO}_{4} / \mathrm{GFR}$ increased in both groups during calcium loading after the second hour, indicating a relative decrease in phosphate excretion. The response
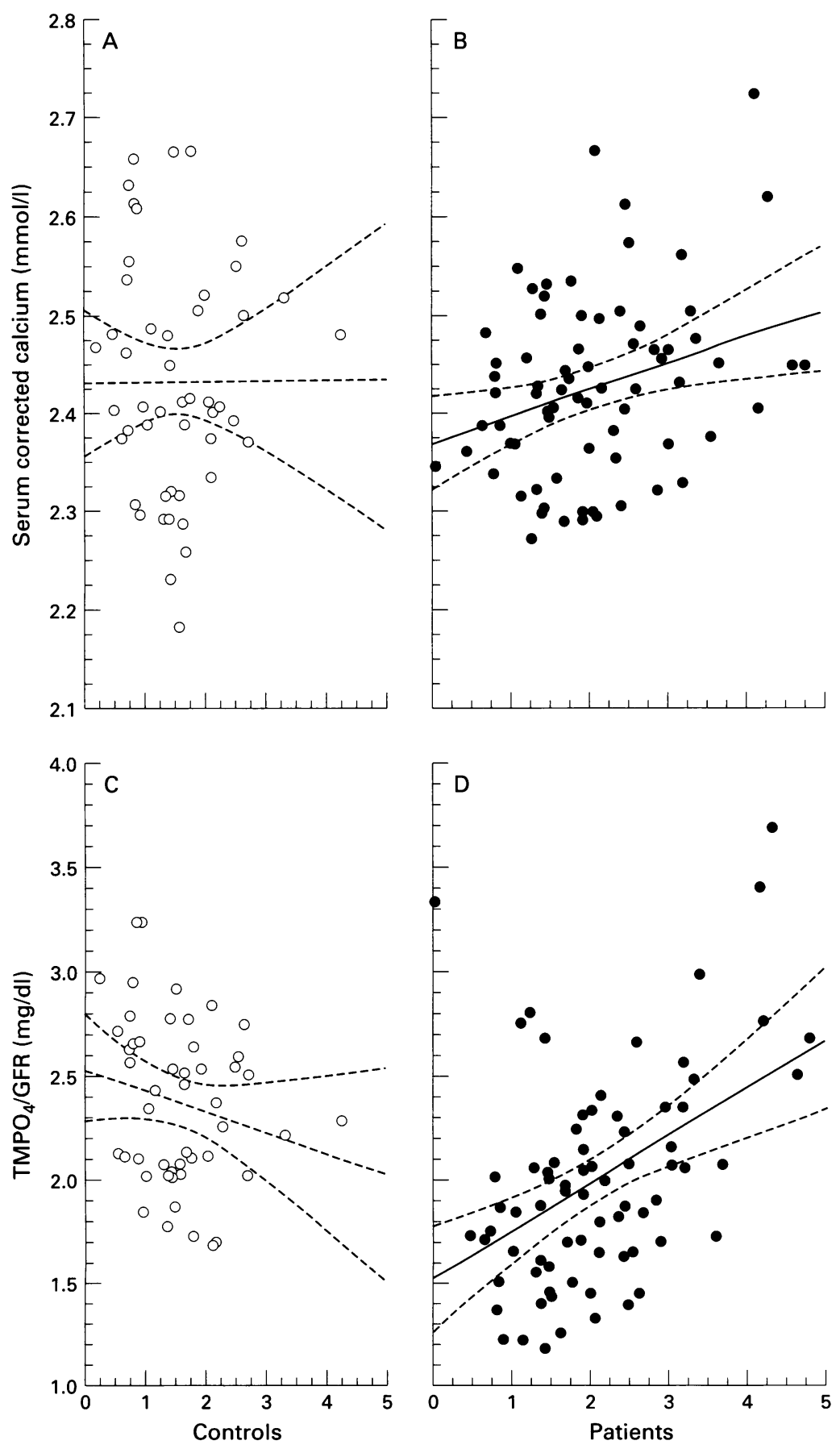

Urine calcium clearance $(\mathrm{ml} / \mathrm{min})$

Figure 5 Scatter diagrams and regression lines of serum corrected calcium $(A$ and $B)$ and $\mathrm{TMPO}_{4} / \mathrm{GFR}$ (C and $\left.D\right)$ against urine calcium clearance in controls and patients using data pooled from the calcium loading test results. profiles in the two groups were parallel $(\mathrm{p}<$ 0.05 ), with values in the patients being significantly lower (showing greater phosphaturia) than in the controls throughout the test $(\mathrm{p}=$ 0.0282).

The percentage change in phosphaturia in response to the calcium loading test was calculated by subtracting the mean value obtained from the first two hours of the test from the mean values obtained from the last two hours and expressing this as a percentage of the mean value of the first two hours' results. The median percentage increase in the controls was $13.8 \%$ (intraquartile range 2.05-17.99) and was $22.4 \%$ in the patients (intraquartile range 14.05-32.7). The patients therefore showed a greater fall in phosphaturia in response to calcium loading ( $p=0.052$, Mann Whitney $U$ test).

There was no difference in the response of serum corrected calcium to the calcium load between patients and controls (fig 3A). There was, however, a significant increase in serum corrected calcium from the basal values (hours -2 and -1 ) to the post-dose values (hours 2 and 3 ) in both groups. In the controls, serum corrected calcium increased from a median value of $2.38 \mathrm{mmol} / \mathrm{l}$ (intraquartile range 2.31 2.44 ) to $2.49 \mathrm{mmol} / \mathrm{l}$ (intraquartile range 02.40-2.56) ( $\mathrm{p}=0.0071$, Mann Whitney $\mathrm{U}$ test). In the patients, serum corrected calcium increased from a median value of $2.36 \mathrm{mmol} / \mathrm{l}$ (intraquartile range $2.30-2.41$ ) to $2.46 \mathrm{mmol} / \mathrm{l}$ (intraquartile range 2.43-2.52) ( $p<0.0001)$.

Figure 3B shows calcium clearance response to calcium loading. The response profiles were parallel $(p<0.05)$, with the patients showing a greater mean calcium clearance throughout the test $(p=0.0225)$. Patients had a significantly higher basal (hours -2 and -1 ) calcium clearance values than controls $(p=0.0059$, Mann Whitney $U$ test). The median basal calcium clearance in patients was $1.68 \mathrm{ml} / \mathrm{min}$ (intraquartile range $1.24-2.03$ ) and was 1.04 $\mathrm{ml} / \mathrm{min}$ (intraquartile range $0.71-1.62$ ) in the controls. There was a significant increase in calcium clearance from the basal values to the post-dose values in both groups. In the controls, calcium clearance increased from a median value of $1.04 \mathrm{ml} / \mathrm{min}$ (intraquartile range $0.71-1.62$ ) to $1.94 \mathrm{ml} / \mathrm{min}$ (intraquartile range $1.42-2.58)(\mathrm{p}=0.00075$, Mann Whitney $U$ test). In the patients, calcium clearance increased from a median of $1.68 \mathrm{ml} / \mathrm{min}$ (intraquartile range $1.24-2.03$ ) to $2.60 \mathrm{ml} / \mathrm{min}$ (intraquartile range $1.51-3.27)(p=0.0014)$.

In both patients and controls there was a significant positive relation between the pooled $\mathrm{TmPO}_{4} / \mathrm{GFR}$ values and serum corrected calcium by regression analysis (fig 4). Controls: $\mathrm{TmPO}_{4} / \mathrm{GFR}=-2.999+2.2057 \times$ serum cor rected calcium (se of regression parameter: $0.371, \mathrm{t}(47)=5.95, \mathrm{p}<0.00001)$; patients: $\mathrm{TmPO}_{4} / \mathrm{GFR}=-3.277+2.1789 \times$ serum corrected calcium (se of regression parameter $0.608, \mathrm{t}(72)=3.586, \mathrm{p}=0.00061)$.

There was no difference between the slopes of the regression lines (95\% confidence interval (CI) for difference between slopes: -1.37 to 1.46), but the regression line for the patients 


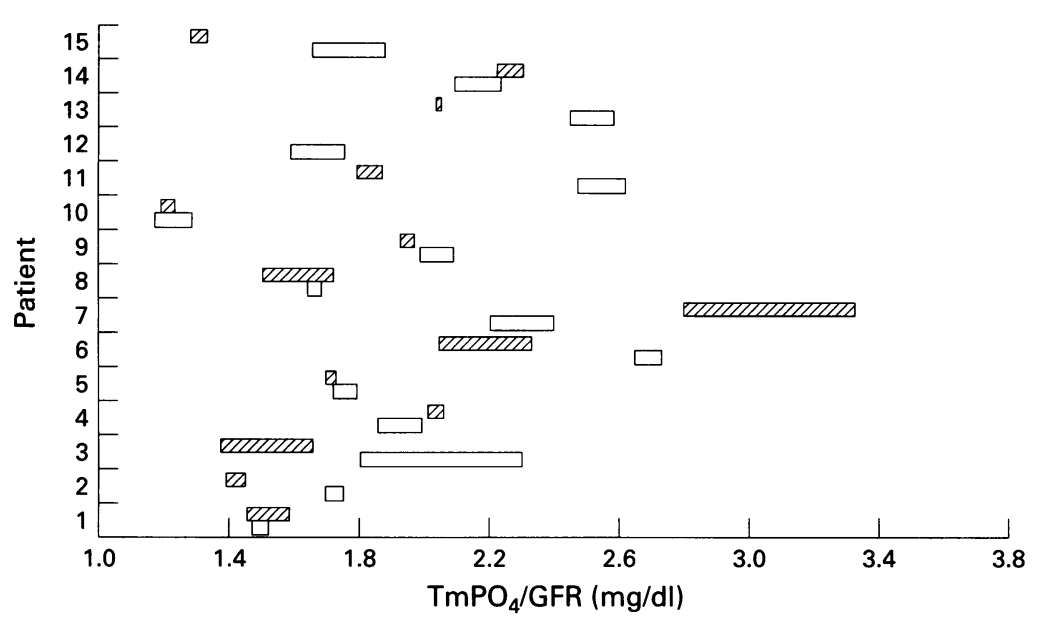

Figure 6 Inter-and intra-individual variation in $\mathrm{TmPO}_{4} / G \mathrm{FR}$ in patients. The shaded bars represent the lower and higher of patients' two consecutive days' results prior to being recruited into the study; the unshaded bars represent the lower and higher of the two consecutive results of the first two hours of the calcium loading test.

was at a significantly $(\mathrm{p}<0.05)$ lower level than that for the controls ( $95 \% \mathrm{CI}$ for vertical difference between the lines: -0.515 to -0.214 ), indicating a greater phosphaturia for any given serum calcium concentration. To exclude the possibility that the difference between the regression lines was an age related effect, the analysis was repeated after excluding the three patients over 60 years of age $(66,70$ and 75 years). Again, there was no difference between the slopes of the regression lines (95\% $\mathrm{CI}-0.5$ to 2.3 ) and the regression line for the patients was significantly lower than that of the controls $(95 \%$ CI for vertical difference: -0.384 to -0.093$)$.

In the patients there was a significant positive relation between serum corrected calcium and urine calcium clearance, but in the controls there was no such relation (figs $5 \mathrm{~A}$ and 5B). Controls: serum corrected calcium $=$ $2.432+0.00054 \times$ calcium clearance (se of regression parameter: $0.022, \mathrm{t}(47)=0.0245, \mathrm{p}$ $=0.98)$; patients: serum corrected calcium $=$ $2.369+0.0103 \times$ calcium clearance $(\mathrm{se}$ of regression parameter: $0.0103, \mathrm{t}(72)=2.625, \mathrm{p}$ $=0.011$ ).

In the patients there was a significant positive relation between the $\mathrm{TmPO}_{4} / \mathrm{GFR}$ and urinary calcium clearance, but in the controls there was no such relation (figs $5 \mathrm{C}$ and 5D). Controls: $\mathrm{TmPO}_{4} / \mathrm{GFR}=2.476-0.0741$ $\times$ calcium clearance (se of regression parameter: $0.0647, \mathrm{t}(47)=-1.144, \mathrm{p}=0.26)$; patients: $\mathrm{TmPO}_{4} / \mathrm{GFR}=1.521+0.227 \times$ calcium clearance (se of regression parameter: 0.054, $\mathrm{t}(72)=4.207, \mathrm{p}<0.0001)$.

The inter- and intra-individual variation in $\mathrm{TmPO}_{4} / \mathrm{GFR}$ were calculated in the patients most recent pair of results prior to the study, in the two basal one hour collections during the study (fig 6) and in all these values pooled. The interindividual CVs were $20.7 \%, 25.2 \%$ and $28.7 \%$, respectively, whereas the intraindividual CVs were $6.6 \%, 7.6 \%$ and $13.2 \%$, respectively.

In both patients and controls the pooled serum corrected calcium concentrations fell with increasing PTH values (fig 7A). Controls: serum corrected calcium $=2.584-0.08 \times$ serum PTH (se of regression parameter: $0.022, \mathrm{t}(48)=-3.6988, \mathrm{p}=0.0006)$; patients: serum corrected calcium $=2.491-0.0106 \times$ serum PTH (se of regression parameter: $0.0106, \mathrm{t}(72)=-3.278, \mathrm{p}=0.0016)$.

There was a significant difference between slopes (95\% CI for difference between slopes: -0.089 to -0.00066$)$, but there was no difference in vertical separation $(95 \%$ CI for vertical separation: -0.029 to +0.0453 ).

The phosphate clearance for a given serum calcium concentration was expressed as the $\mathrm{TmPO}_{4} / \mathrm{GFR}$ against the serum corrected calcium. The $\mathrm{TmPO}_{4} / \mathrm{GFR}$ :serum corrected calcium ratio fell with increasing $\mathrm{PTH}$ concentrations (fig 7B) in patients but not in controls. Neither of the regression parameters reach statistical significance; however, there is a signifi-
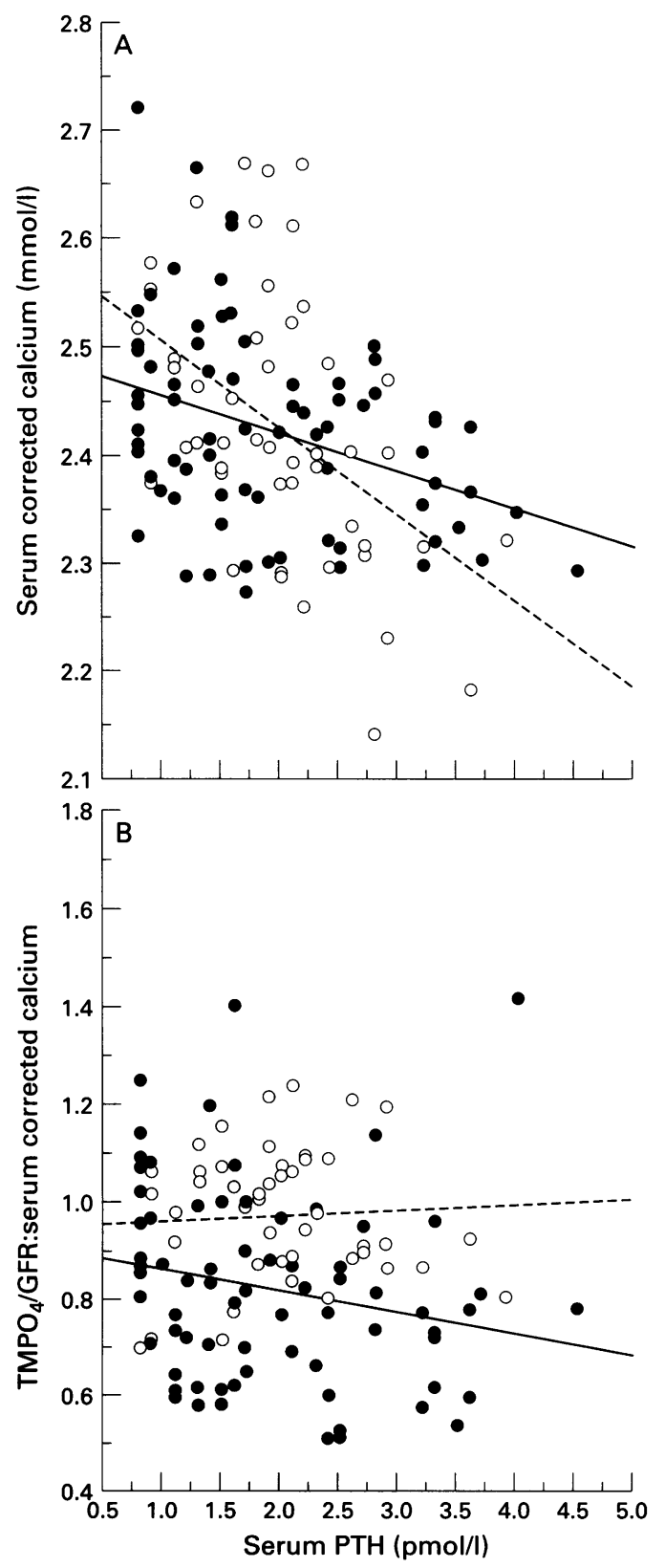

Figure 7 Scatter diagrams and regression lines of $(A)$ serum corrected calcium and (B) the TMPO $/$ /GFR to serum corrected calcium ratio against serum PTH using data pooled from the calcium loading test results. The filled points represent patients' results and the unfilled points the controls' results. Their two regression lines are indicated by solid and broken lines, respectively. 

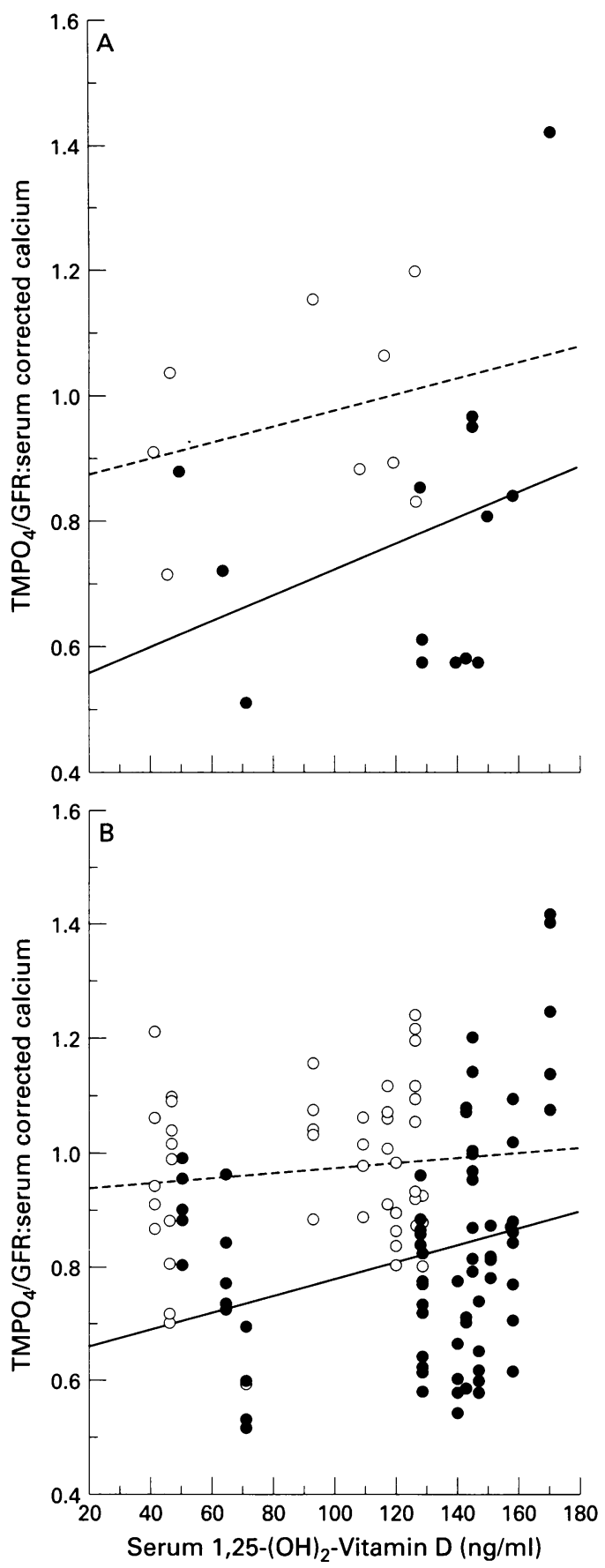

Figure 8 Scatter diagrams and regression lines of $(A)$ $\mathrm{TmPO}_{4} / G F R$ to serum corrected calcium ratio (hour -2 only) and (B) pooled data against fasting serum

$1,25-(\mathrm{OH})_{2}$-vitamin $D$. The filled points represent patients' results and the unfilled points the controls' results. Their two regression lines are indicated by solid and broken solid lines, respectively.

cant difference between the two lines in vertical separation (95\% CI for vertical separation: $0.086-0.215)$. Patients therefore had a significantly lower ratio (greater phosphaturia) for any given $\mathrm{PTH}$ value.

Fasting 1,25-(OH) ${ }_{2}$-vitamin D concentrations in patients were significantly higher than those in the controls (fig 8A: median of patients values $143 \mathrm{ng} / \mathrm{ml}$; median of controls $113, \mathrm{ng} / \mathrm{ml} ; \mathrm{p}=0.0039$, Mann Whitney U test). However, increasing phosphaturia against the calcium concentration (lower $\mathrm{TmPO}_{4} /$ GFR ratio) was not positively correlated with increasing $1,25-(\mathrm{OH})_{2}$ - vitamin $\mathrm{D}$ concentrations in first fasting samples in patients or controls (fig $8 \mathrm{~A}$ ) or additionally during calcium loading (fig $\mathrm{B}$ ). In figs $8 \mathrm{~A}$ and $8 \mathrm{~B}$ the regression lines representing the patients and controls are significantly separated (95\% CI for vertical separation: $0.039-0.445$ and $0.115-0.255$, respectively).

The results collected during the calcium loading tests were used to classify the patients on the basis of previously described criteria. ${ }^{6}$ Five patients had absorptive hypercalciuria defined by a normal mean fasting urine calcium clearance (using a reference range of 0.35-1.92 $\mathrm{ml} / \mathrm{minute}$ derived non-parametrically from our normal subjects) plus a urine calcium excretion exceeding $0.2 \mathrm{mg} / \mathrm{mg}$ creatinine in any of the three urine collections after the calcium load. None of our patients was classified as having renal hypercalciuria within the criteria of increased fasting urine calcium clearance plus raised serum fasting PTH and normal corrected serum calcium. Five of our patients, however, could be classified as having a renal phosphate leak on the basis of a fasting hypercalciuria plus a normal serum fasting PTH. Eight patients had a phosphate leakage as indicated by a decreased mean fasting $\mathrm{TmPO}_{4} / \mathrm{GFR}$ (using a reference range derived from the control subjects of $1.72-2.84 \mathrm{mg} / \mathrm{dl}$ ), only one of which was not associated with other abnormalities. Twelve patients had an increased serum fasting vitamin $\mathrm{D}$ concentration. Of these, three were associated only with a decreased $\mathrm{TmPO}_{4} / \mathrm{GFR}$ and one was an isolated abnormality.

\section{Discussion}

Our results possibly suggest that the previous classification of some patients with renal calculi as having absorptive hypercalciuria, renal hypercalciuria, renal phosphate leak, or primary enhancement of $1,25-(0 \mathrm{H})_{2}$-vitamin $\mathrm{D}$ production, might be artificial. Patients with hypercalciuria exhibit homogeneity in the sense of behaving significantly differently from control subjects in terms of their $\mathrm{TmPO}_{4} / \mathrm{GFR}$ for a range of serum calcium concentrations. This is emphasised by the respective regression lines being both significantly (fig 4) apart and parallel. If the group actually had absorptive hypercalciuria by the conventionally presumed mechanism, ${ }^{21}$ then we would expect reduced phosphate excretion (as PTH is suppressed) in comparison with controls, but the reverse was the case (figs 2 and 4 ).

Conversely, if patients had renal hypercalciuria by the conventionally understood mechanism, ${ }^{22}$ impaired tubular reabsorption of calcium would reduce the circulating serum calcium and cause an increase in PTH, so reducing the $\mathrm{TmPO}_{4} / \mathrm{GFR}$. The patients, as a group, have a reduced $\mathrm{TmPO}_{4} / \mathrm{GFR}$ compared with controls (fig 4 ). If they were primarily failing to reabsorb calcium in the renal tubule, however, then we would expect increased calcium clearance to be associated with either reduced serum calcium (that is, impaired tubular reabsorption of calcium thereby reducing serum calcium for correction by PTH) or no change at all, but the reverse process 
occurred (fig 5B)-that is, increasing serum calcium concentrations are driving the hypercalciuria. There was no difference between groups with regard to serum corrected calcium during calcium loading (fig $3 \mathrm{~A}$ ), but patients cleared more calcium into urine during calcium loading (fig 3B). This could be explained by higher rates of calcium gut absorption being matched by a proportional increase in renal calcium clearance in patients and not renal calcium leakage.

Other important mechanisms, as conventionally described, ${ }^{6}$ are renal phosphate leak and primary enhancement of $1,25-(\mathrm{OH})_{2}-$ vitamin $\mathrm{D}$ synthesis. Such a leak could be driven by PTH. The parallel regression lines in fig 4 favour (arguably) the same regulation of excretion in both groups. Perhaps a genetically determined variation (patients $v$ controls) in end organ response to PTH explains the observed difference. Phosphate excretion, however, can change independently of PTH and other phosphate regulation mechanisms are under consideration. ${ }^{14}{ }^{15}$ Serum phosphate concentration alone did not distinguish the groups in any way at all, the key factor being that for a given concentration of serum calcium there is a relatively greater degree of phosphaturia in the patients (fig 4).

Animal models have shown that increased $\mathrm{PTH}$, in response to reduced serum calcium, stimulates renal synthesis of $1,25-(\mathrm{OH})_{2}-$ vitamin $\mathrm{D}$ in the renal proximal tubule. Distal tubular synthesis, however, is a function of the calcitonin concentration. ${ }^{23}$ Evidence over the past two years from Giannini et $a l{ }^{24}$ contrary to other, older evidence, ${ }^{21}$ has shown a positive correlation between $1,25-(\mathrm{OH})_{2}$-vitamin D and urinary calcium in pooled categories of patients with idiopathic hypercalciuria. The $1,25-(\mathrm{OH})_{2}$-vitamin $\mathrm{D}$ receptor is known to be present in most cells of the body ${ }^{25}$ and, in the context of bone mineralisation, twin studies have shown that bone density is dependent upon vitamin $\mathrm{D}$ receptor genotype. ${ }^{26}$ Broader differences between individuals for any 1,25$(\mathrm{OH})_{2}$-vitamin D concentration may be concealed by their receptor genotype, and all of these considerations are complicated by vitamin $\mathrm{D}$ binding protein and competition for vitamin $\mathrm{D}$ binding sites. ${ }^{13}$ Nevertheless, we found significant differences in $1,25-(\mathrm{OH})_{2}-$ vitamin $\mathrm{D}$ concentrations in this small study. Why?

In humans there is strong evidence that circulating phosphate concentrations play a major role in the regulation of the concentration of $1,25-(\mathrm{OH})_{2}$-vitamin $\mathrm{D}$; in essence, decreased availability of phosphate increases $1,25-(\mathrm{OH})_{2}$-vitamin $\mathrm{D}$ and vice versa. ${ }^{27}$ The patients with the highest $1,25-(\mathrm{OH})_{2}$-vitamin $\mathrm{D}$ concentrations as a whole (fig $8 \mathrm{~B}$ ) also had the greatest propensity to clear phosphate via the kidney for any serum calcium concentration. Notably, within each group itself, the slopes of the regression lines (fig 8) were contrary to increasing $1,25-(\mathrm{OH})_{2}$-vitamin $\mathrm{D}$, explaining this phenomenon. Patients with renal calculi might absorb relatively more calcium than control subjects according to the relative level of vitamin $\mathrm{D}$ activation at that time. There is notable intra-individual variation in the excretion of calcium in these patients over periods of weeks while there is greater concordance in consecutive samples (fig 1). It is possible that this variation is caused, not by differences in diet, but altered status in the absorption process of the individual, possibly in response to the preceding dietary period. The relative swings in urinary calcium over time could reflect the dietary availability of calcium or, alternatively, the whole absorptive mechanism could be up regulated and down regulated from time to time via activation of vitamin $\mathrm{D}$. The key to such apparent fluctuations could rest in the two to three week half life of cholecalciferol ${ }^{12}$ and probably more critically the presumed six hour half life of $1,25-(\mathrm{OH})_{2}$-vitamin $\mathrm{D}^{12}$ Longitudinal studies of patients are necessary to ascertain whether this is true. The process of limiting gut absorption of calcium for therapeutic purposes may simply up regulate the mechanism of calcium absorption. In terms of down regulating such a mechanism the key factor might not be the absolute amount of calcium available but when it is available, and this could be important for therapeutic purposes. If a small amount of calcium was more continually available for absorption, then that might down grade the mechanism. It is of particular note that down regulation of phosphaturia (to 'normal') occurs to a proportionally greater extent (fig 2) during calcium loading in the patients with renal calculi than in control subjects, although the patients start in the fasting state with a greater degree of phosphaturia.

Figure 6 illustrates the general problem of intra-individual variation, showing that $\mathrm{TmPO}_{4} / \mathrm{GFR}$ may apparently be different from paired observation to paired observation. It would be of interest to know how consistently patients behave over a period of time in respect of their classifications of absorptive hypercalciuria and renal hypercalciuria. We suspect that there is a mobility between the groups and suggest that this be investigated further.

It may be more advantageous to reduce the amount of calcium absorbed by downgrading the absorption mechanism than by decreasing the amount of calcium in the gut. A downgraded absorption mechanism will leave calcium in the gut to complex oxalate and at such times as there is a relative excess of calcium in the gut this will not be reflected in such a steep rise in urinary calcium. The risk of controlling calcium at the expense of oxalate has been emphasised as calcium oxalate saturation increases rapidly with a small increase in urine oxalate excretion. ${ }^{28}$ It would thus seem more desirable to have a given amount of calcium excreted steadily by the kidney rather than intermittent very high levels balanced by low levels. It may be possible to reduce calcium absorption as a whole on a basis of little but often. Key recent work has shown that in a prospective study the risk of symptomatic stone disease in a cohort of over 45000 men was less for those with higher dietary calcium 
intake. $^{29}$ Our recommendations for further research are listed below.

- To consider, for a range of calcium intakes, whether the calcium and indirectly the oxalate absorption mechanisms can be down regulated (a) overall and (b) for the purpose of avoiding urinary surges by altering the distribution of calcium in the diet or its chelation.

- To perform longitudinal vitamin D metabolite studies on patients with renal calculi comparing vitamin $\mathrm{D}$ with urinary calcium and oxalate as an explanation of their natural variation.

- To consider the appropriateness of 'normal' vitamin $\mathrm{D}$ dietary supplementation in individuals with 'exaggerated' phosphaturic response to fasting.

We are grateful to Ms P Cowley, Chief Dietician, Wrexham Maelor Hospital, for advice and for care of the patients and to Miss PA Davies for arranging the calcium loading tests and for her help in preparing this manuscript. We are grateful to $\mathrm{Mr} R$ Henly and $\mathrm{Dr}$.hn from the Department of $\mathrm{Mr}$ Depart grateful to Mr $R$ Biochemistry, University Hospital of Wales, Cardiff, for advice and $1,25-(\mathrm{OH})_{2}$-vitamin D and PTH assays.

1 Coe FL, Parks JH, Asplin JR. The pathogenesis and treatment of kidney stones. $N$ Engl $f$ Med 1992;327: 1141-52.

2 Sierakowski R, Finlayson B, Landes RR, Finlayson CD, Sierakowski N. The frequency of urolithiasis in hospital discharge diagnoses in the United States. Invest Urol 1978; dis:438-41.

3 Johnson CM, Wilson DM, O'Fallon WM, Malek RS, Kurland LT. Renal stone epidemiology: a 25 year study in Rochester, Minnesota. Kidney Int 1979;16:624-31.

4 Norlin A, Lindell B, Granberg P-O, Lindvall N. Urolithiasis: a study of its frequency. Scand $\mathcal{F}$ Urol Nephrol 1976;10:150-3.

5 Yoshida O, Okada Y. Epidemiology of urolithiasis in Japan: a chronological and geographical study. Urol Int 1990;45: a chronologi

6 Pak CYC. Kidney stones. In: Wilson JD, Foster DW, eds. Williams Textbook of endocrinology. 8th edn. London: Saunders, 1992:1519-35.

7 Walton RJ, Bijvoet OLM. Nomogram for derivation of renal threshold phosphate concentration. Lancet 1975;ii:309-10.

8 Eaton SB, Nelson DA. Calcium in evolutionary perspective. Am $\mathcal{F}$ Clin Nutr 1991;54(Suppl 1):281S-7S.
9 Heaney RP, Barger-Lux MJ. ADSA Foundation Lecture Low calcium intake: the culprit in many chronic diseases. $f$ Dairy Sci 1994;77:1 155-60.

10 Barger-Lux MJ, Heaney RP. The role of calcium intake in preventing bone fragility, hypertension, and certain canpreventing bone fragility, hypertension, and

11 Department of Health. Dietary reference values for food energy and nutrients for the United Kingdom. Report on Health and Social Subjects. London: HMSO, 1994:41:124

12 Taylor WH. Renal calculi and self medication with multivitamin preparations. Clin Sci 1972;42:515-22.

13 Fraser DR. Fat-soluble vitamins. Lancet 1995;345:104-7.

4 Cai Q, Hodgson SF, Kao PC, Lennon VA, Klee GG, Zinsmeister AR, Kumar R. Brief report: Inhibition of renal phosphate transport by a tumor product in a patient with oncogenic osteomalacia. $N$ Engl $\Im$ Med 1994;330:1645-9.

15 Econs MJ, Drezner MK. Tumor-induced osteomalacia unveiling a new hormone [editorial]. $N$ Engl $f \mathrm{Med}$ 994:330:1679-81.

16 Gardner MJ, Altman DG. Statistics with confidence. London BMJ Publishing Group, 1989:44-6

17 Snedecor GW, Cochran WG. Statistical methods. 7th edn. Ames: Iowa State University Press, 1980:238-48.

18 Fraser CG, Harris EK. Generation and application of data on biological variation in clinical chemistry. Crit Rev Clin Lab Sci 1989;27:409-37.

19 Morrison DF. Multivariate statistical methods. 2nd edn. Tokyo: McGraw-Hill Kogakusha, 1976:153-60.

20 Shephard MDS, Penberthy LA, Fraser CG. Short and longterm biological variation in analytes in urine of apparently healthy individuals. Clin Chem 1981;27:569-73.

$21 \mathrm{Pak}$ CYC. Physiological basis for absorptive and renal hypercalciurias. Am $\mathcal{f}$ Physiol 1979;237:F415-23.

22 Coe FL, Canterbury JM, Firpo JJ, et al. Evidence for secondary hyperparathyroidism in idiopathic hypercalciuria. 7 Clin Invest 1973;52:134-42.

23 Holick MF. Vitamin D. Biosynthesis, metabolism, and mode of action. In: DeGroot LJ, Besser GM, Cahill GF Jr, Marshall JC, Nelson, DH, Odell WS, Potts JT Jr, Rubenstein shall JC, Nelson, DH, Odell WS, Potts JT Jr, Rubenstein $\mathrm{AH}$, Steinberger E, eds. Endocrinolog

24 Giannini S, Nobile M, Castrignano R, Pati T, Tasca A, Villi G, Pellegrini F, D'Angelo A. Possible link between vitamin $\mathrm{D}$ and hyperoxaluria in patients with renal stone disease. Clin Sci 1993;84:51-4.

25 Sandgren ME, Bronnegard M, DeLuca HF. Tissue distribution of the 1,25-dihydroxyvitamin $D_{3}$ receptor in the male rat. Biochem Biophys Res Commun 1991;181: 611-16.

26 Spector TD, Keen RW, Arden NK, Morrison NA, Major PJ, Nguyen TV, et al. Influence of vitamin D receptor genotype Nguyen TV, et al. Influence of vitamin D receptor genotype on bone mineral density in postmenopausa

27 Portale AA, Halloran BP, Murphy MM, Morris RC Jr. Oral intake of phosphorus can determine the serum concentration of 1,25-dihydroxyvitamin $D$ by determining its production rate humans. $\mathcal{F}$ Clin Invest 1986;77:7-12.

28 Borsatti A. Calcium oxalate nephrolithiasis: defective oxalate transport. Kidney Int 1991;39:1283-98.

29 Curhan GC, Willett WC, Rimm EB, Stampfer MJ. A prospective study of dietary calcium and other nutrients and the risk of symptomatic kidney stones. $N$ Engl $₹ \mathrm{Med}$ 1993;328:833-8. 